\title{
EXPRESSIVE WRITING TREATMENT TERHADAP STRES MAHASISWA DI PRODI S1 KEPERAWATAN
}

\author{
Expressive Writing Intervention for Academic Stress of Nursing Students
}

\author{
Nety Mawarda Hatmanti, Rusdianingseh \\ Program Studi S1 Keperawatan UNUSA \\ e-mail: nety.mawarda@unusa.ac.id
}

\begin{abstract}
ABSTRAK
Mahasiswa dalam tahapannya mengalami masa kritis dan transisi sebelum menjalani kehidupan sesungguhnya di masyarakat. Pada tahap ini mereka mengalami berbagai hal adaptasi dan tekanan dari lingkungan di sekitarnya. Penelitian ini bertujuan untuk menganalisis pengaruh expressive writing treatment terhadap stress mahasiswa. Desain dalam penelitian ini menggunakan metode deskriptif analitik dengan pre and post test control group design. Populasi penelitian ini adalah 152 mahasiswa Prodi s1 Keperawatan di semester VI. Pengambilan sampel menggunakan tehnik Simple Random Sampling sehingga didapatkan jumlah sampel perlakuan 64 mahasiswa, sedangkan kelompok kontrol 64 mahasiswa. Hasil penelitian menunjukkan rata-rata skor stres kelompok yang tidak diberikan expressive writing treatment (control) adalah 130,7, sedangkan ratarata skor stres kelompok yang diberikan expressive writing treatment adalah 124,95. Menggunakan Mann Whitney test didapatkan hasil bahwa ada perbedaan skor stress yang diberikan dan tidak diberikan Expressive writing Treatment ( $p$-value $=0,024)$. Hal ini menandakan pemberian expressive writing treatment dapat berpengaruh pada skor tingkat stres. Dosen bisa menerapkan tehnik ini untuk menggali dan mengungkapkan perasaan mahasiswa selama kegiatan di kampus agar mahasiswa bisa mereduksi stres yang dirasakan selama fase kehidupannya.
\end{abstract}

Kata Kunci :expressive writing treatment, mahasiswa, stress akademik

\section{ABSTRACT}

Students will experience a critical and transition period before living their real lives society. They will wxperience various adaptations and pressure from the surrounding environment. This study is analitic descriptive with pre and post test control group design. This research population is 152 nursing students in $6^{\text {th }}$ semester. Sampling using simple random sampling technique and get the number of treatment group=64 students and control group $=64$ students. Result showed that the average stress score of the group not given expressive writing treatment (control) was 130,7, while the average group stress score given expressive writing treatment is 124,95. Mann Whitney test results showed that there were differences in stress scores given and not given expressive writing treatment ( $p$-value $=0,024$ ). This indicates that giving expressive writing treatment can affects that stress level score. Lecturers can apply this technique to explore and express student feelings during activities on campus so that student can reduce the stress felt during the phase of their lives.

Keywords : expressive writing treatment, students, academic stress

\section{PENDAHULUAN}

Mahasiswa merupakan salah satu kelompok khusus di masyarakat yang sedang mengalami masa kritis dan transisi sebelum mereka menghadapi kehidupan yang sebenarnya di lingkungan masyarakat. Mereka akan berhadapan dengan beberapa tekanan seperti belajar menuntut ilmu dan ada yang sebagian bekerja untuk memenuhi kebutuhan. Mahasiswa pada masa transisi dan kritis banyak mendapatkan tekanan dari lingkungan sekitar diantaranya hubungan dengan teman, tekanan untuk belajar, permasalahan dengan dosen, teman dan keluarga, masalah kesehatan juga tentang cara beradaptasi. Hal-hal tersebut bisa menimbulkan kondisi stress pada mahasiswa saat menjalani kehidupan sehari-hari. (Hou, Linping., Liu, Yaozhong, 2016).

Mahasiswa dalam mengurangi stress bisa dilakukan dengan beberapa hal sehingga tidak menjadi hal yang mengancam bagi kehidupannya. Klein dan Adriel (2001) dalam 
Rahmawati, Marieta (2014) menyatakan bahwa tehnik menulis ekspresif bisa dijadikan sebagai salah satu metode intervensi untuk menurunkan seseorang untuk berfikir tentang pengalaman terhadap stress, yang harapannya bisa membebaskan sumber informasi bagian working memory.

Purwati, Susi (2012) melakukan penelitian pada mahasiswa Ilmu Keperawatan Universitas Indonesia mendapatkan data bahwa sebagian besar berada dalam tingkat stress sedang dan responden didominasi oleh mahasiswa perempuan. Hatmanti, Nety Mawarda (2018) dalam penelitiannya menyebutkan bahwa dari 240 mahasiswa, 62\% (149 mahasiswa) berada dalam kategori stress berat. Peneliti melakukan studi pendahuluan pada mahasiswa semester VI T.A 2018/2019 pada 10 mahasiswa perempuan di bulan Februari 2019 didapatkan data bahwa pada saat suntuk 8 mahasiswa lebih memilih jalan-jalan ke mall dekat kampus untuk menghilangkan penat kegiatan di kampus dan 2 mahasiswa memilih untuk curhat dengan teman yang satu geng/kelompok.

Menulis ekspresif merupakan suatu proses yang membutuhkan integrasi antara pikiran, afeksi dan motorik. Saat seseorang menuliskan secara ekspresif tentang apa yang dirasakannya, maka hal tersebut yang dituliskan adalah mengenai bagaimana perasaan pada saat mengalami hal yang dialami tersebut, kemudian melakukan evaluasi kembali setiap yang telah dituliskan dan mengarahkan pikiran ke dalam persepsi atau pemikiran baru. (Money, Espie \& Broomfield, 2009 dalam Fitria Ida, dkk, 2016). Kegiatan menulis tersebut akan berdampak pada kondisi psikologis pada seseorang baik dalam hal menuliskan hal-hal yang bersifat positif maupun negative. (Kallay \& Baban, 2008)

Berdasarkan uraian di atas telah terlihat jelas manfaat dari menulis ekspresif bagi seseorang baik dilihat dari kesejahteraan fisik maupun psikologis. Penulis tertarik untuk memfokuskan penelitian tentang mereduksi tingkat stress pada mahasiswa di Prodi S1 Keperawatan FKK Unusa.

\section{METODE}

Penelitian ini menggunakan metode deskriptif analitik dengan pre and post test control group design. Populasi penelitian ini adalah mahasiswa aktif Program Studi S1 Keperawatan Fakultas Keperawatan dan Kebidanan UNUSA tahun akademik 2018/2019 yang semester VI berjumlah 152 mahasiswa. Pengambilan sampel dilakukan dengan menggunakan tehnik Simple Random Sampling, sehingga didapatkan jumlah kelompok perlakuan $=64$ mahasiswa dan kelopok kontrol 64 mahasiswa. Pengukuran variable dalam penelitian ini diantaranya : tingkat stress menggunakan kuesioner DASS (Depression Anxiety Stress Scale) yang dimodifikasi.

\section{HASIL DAN PEMBAHASAN HASIL}

Hasil dalam penelitian ini ada data umum dan data umum. Data umum terdiri dari jenis kelamin, tempat tinggal selama perkuliahan dan kegiatan selain perkuliahan. Data khusus terdiri dari : tingkat stress akademik (pre dan post test) kelompok perlakuan dan Expressive Writing Treatment terhadap stress pada kelompok perlakuan

1. Data Umum

a. Jenis Kelamin

Tabel 1 Distribusi Frekuensi Responden menurut Jenis Kelamin pada Kelompok Perlakuan

\begin{tabular}{cccc}
\hline No & Jenis Kelamin & Frekuensi & Persentase $(\%)$ \\
\hline 1. & Laki-laki & 9 & 14,06 \\
2. & Perempuan & 55 & 85,94 \\
\hline & Total & 64 & $100 \%$ \\
\hline
\end{tabular}

Sumber: Data Primer, 2019

Tabel 1 menunjukkan bahwa dari 64 responden didapatkan hampir seluruhnya $(85,94 \%)$ berjenis kelamin perempuan.

b. Tempat Tinggal selama Perkuliahan

Tabel 2 Distribusi Frekuensi Responden menurut tempat tinggal selama perkuliahan

\begin{tabular}{|c|c|c|c|}
\hline No & Tempat Tinggal & Frekuensi & $\begin{array}{c}\text { Persentase } \\
(\%)\end{array}$ \\
\hline 1. & $\begin{array}{c}\text { Rumah orang } \\
\text { tua }\end{array}$ & 43 & 67,19 \\
\hline 2 & Rumah saudara & 5 & 7,81 \\
\hline 3. & Kost & 12 & 18,74 \\
\hline 4. & Asrama & 2 & 3,13 \\
\hline
\end{tabular}




\begin{tabular}{cccc}
\hline 5. & Kontrak & 2 & 3,13 \\
6. & Rumah sendiri & 0 & 0 \\
\hline & Total & 64 & $100 \%$ \\
\hline
\end{tabular}

Sumber : Data Primer, 2019

Tabel 2 menunjukkan bahwa dari 64 responden didapatkan sebagian besar $(67,19 \%)$ selama perkuliahan tinggal bersama dengan orang tuanya.

3. Kegiatan selain Perkuliahan

Tabel 3 Distribusi frekuensi responden menurut kegiatan selain perkuliahan

\begin{tabular}{|c|c|c|c|}
\hline No & Kegiatan & Frekuensi & $\begin{array}{c}\text { Persentase } \\
(\%)\end{array}$ \\
\hline 1. & $\begin{array}{c}\text { Organisasi } \\
\text { kampus }\end{array}$ & 28 & 43,75 \\
\hline 2. & $\begin{array}{l}\text { Organisasi luar } \\
\text { kampus }\end{array}$ & 12 & 18,75 \\
\hline 3. & Bekerja & 4 & 6,25 \\
\hline 4. & $\begin{array}{l}\text { Tidak ada } \\
\text { kegiatan }\end{array}$ & 20 & 31,25 \\
\hline 5. & Lain-lain & 0 & 0 \\
\hline & Total & 64 & $100 \%$ \\
\hline
\end{tabular}

Sumber : Data Primer, 2019

Tabel 3 menunjukkan bahwa dari 64 responden didapatkan hampir setengahnya $(43,75 \%)$ selama perkuliahan mengikuti kegiatan organisasi di kampus.

4. Tingkat Stress Mahasiswa (pre-test)

Tabel 4 Distribusi frekuensi responden menurut tingkat stress mahasiswa (pre-test)

\begin{tabular}{cccc}
\hline Minimum & Maximum & Mean & $\begin{array}{c}\text { Std. } \\
\text { Deviation }\end{array}$ \\
\hline 85,00 & 173,00 & 127,94 & 16,89 \\
\hline
\end{tabular}

Sumber : Data Primer, 2019

Tabel 4 menunjukkan bahwa rentang skor stres mahasiswa sebelum dilakukan expressive writing treatment $85,00-173,00$.

5. Tingkat Stress Mahasiswa (post-test)

Tabel 5 Distribusi frekuensi responden menurut tingkat stress mahasiswa (post-test)

\begin{tabular}{|c|c|c|c|}
\hline Minimum & Maximum & Mean & $\begin{array}{c}\text { Std. } \\
\text { Deviation }\end{array}$ \\
\hline
\end{tabular}

$\begin{array}{llll}77,00 & 179,00 & 124,95 & 16,92\end{array}$

Tabel 5 menunjukkan bahwa rentang skor stress mahasiswa setelah dilakukan expressive writing treatment $77,00-179,00$

6. Expressive Writing Treatment dengan Tingkat Stres

Tabel 6 Hasil Uji expressive writing treatment dengan tingkat stress

\begin{tabular}{ccc}
\hline Statistik Uji & Nilai $\mathrm{z}_{\text {score }}$ & $p$-value \\
\hline Wilcoxon Signed Ranks Test & $-2,258$ & 0,024 \\
\hline
\end{tabular}

Tabel 6 menunjukkan bahwa dari hasil uji Wilcoxon Signed Ranks Test dengan nilai kemaknaan $\alpha=0,05$, didapatkan nilai $\mathrm{p}$-value $=$ 0,024 yang berarti p-value $<\alpha$ maka $\mathrm{H}_{0}$ ditolak, artinya ada perbedaan skor stress sebelum dan sesudah diberikan expressive writing treatment.

\section{PEMBAHASAN}

Berdasarkan tabel 4 menunjukkan rentang skor stres mahasiswa berada dalam kategori tingkat stres sangat berat. Hal ini diperoleh dari jawaban responden saat mengisi kuesioner yang diberikan oleh peneliti secara online dengan aplikasi google form. Hampir setengah dari responden $(43,75 \%)$ mengikuti kegiatan organisasi di kampus. Pernyataan ini juga didukung oleh penelitian sebelumnya yang dilakukan oleh Agola dan Ongori (2009) yang menyatakan bahwa tingkat stres akademik pada remaja (dalam penelitian ini termasuk tahap remaja akhir) yaitu mahasiswa tergolong tinggi. Tingkat stres akademik dalam penelitian ini diukur berdasarkan indikator fisik, psikologis/ emosi dan indikator perilaku. Peneliti tidak memunculkan data dari 3 indikator tersebut, hal manakah yang paling tinggi nilainya.

Berdasarkan tabel 6 menunjukkan bahwa pemberian expressive writing treatment dapat memberikan tingkat stress yang berbeda pada responden. Jika dilihat pada deskripsi statistik, rata-rata skor stress sebelum adalah 127,94 sedangkan rata-rata skor stress setelah diberikan expressive writing treatment adalah 124,95. Hal ini menandakan pemberikan expressive writing treatment dapat menurunkan tingkat stress. Sejalan dengan penelitian yang 
dilakukan oleh Muhtadini, Rahmita Laily (2018) bahwa expressive writing memiliki pengaruh untuk menurunkan stress akademik siswa Sekolah Menengah Pertama (SMP) full day school. Peneliti melihat pada saat mahasiswa melakukan kegiatan menulis perasaan yang positif maupun negatif, mereka awalnya bingung dengan apa yang akan ditulis, akan tetapi beberapa saat responden mulai menulis dengan semangat. Dari hasil yang diperoleh peneliti, responden kebanyakan menulis tentang keluh kesah selama proses perkuliahan mulai dari konflik dengan teman pada saat mengerjakan tugas, deadline tugas yang saling bertumpukan, konflik dengan dosen mengenai jadwal perkuliahan. Sedangkan selebihnya lainnya menceritakan tentang masalah pribadi baik dengan orang tua, sahabat maupun pacar.

\section{KESIMPULAN}

Pada penelitian ini dapat disimpulkan beberapa hal diantaranya : pemberian expressive writing treatment dapat menurunkan tingkat stress pada mahasiswa.

\section{DAFTAR PUSTAKA}

Agolla, J.E \& Ongori, H. (2009). An assassment of academic stress among undergraduate students. Academic journals, Educational research and review. Vol 4(2), pp.063-067. Diunduh dari http://www.library.unusa.ac.id pada tanggal 21 Februari 2018 pukul 20.00 WIB

Baker, J.R., Moore, S.M.. (2008). Distress, Coping and Blogging : Comparing New Myspace Users by Their Intention to Blog. Cyber Psychology and Behaviour. Volume 1 Nomor 11. Diunduh dari http://www.googlescholar.com pada tanggal 27 Februari 2019 pukul 12.00 WIB

Braham (1990). Gejala Stres. Indonesian Psychological Journal. Anima. No.48. Volume XII. Juli September 1997.

Crowford, J.C \& Henry, J.D. (2003). The Depression Anxiety Stress Scale (DASS) : Normative data and latent structure in a large non clinical sample. British Journal of Clinical Psycology, 42, 111-131. Diunduh dari website http://www.googlescholar.com pada tanggal 05 Maret 2018 jam 08.30 WIB.

Fitria, Ida., Faradina, Syarifah., Rizqina, Fathi., Jannah, Taifatul., Fajri, Ayu., Hadi, Fajmal., Maya Sari, Ratna., A'la, Nurul. (2016). Menulis Ekspresif untuk Anak Jalanan : "Suatu Metode Terapi Menulis dalam Diary melalui Modul Eksperimen". (2016). Jurnal Psikoislamedia. Volume 1 Nomor 1. April 2016. Diunduh dari http://www.googlescholar.com pada tanggal 27 Februari 2019 pukul 12.00 WIB

Govarest, S \& Gregoire, J. (2004). Stressfull academic situasions : study on appraisal variables in adolescence. British Journal of Clinical Psycology, 54, 261-271. Diunduh dari http://www.googlescholar.com pada tanggal 06 Maret 2018 pukul 10.00 WIB

Hatmanti, Nety Mawarda. (2015). Tingkat Stres dengan Siklus Menstruasi pada Mahasiswa. Jurnal Ilmiah Kesehatan. Vol.8 No.1. Diunduh dari website http:www.googlescholar.com pada tanggal 10 Agustus 2018 pukul 10.00 WIB.

Hatmanti, Nety Mawarda., Septianingrum, Yurike. (2019). Faktor-faktor yang Mempengaruhi Stres Akademik Mahasiswa Keperawatan. Jurnal Ilmiah Keperawatan. Volume 5 Nomor 1 Maret Tahun 2019. Diunduh dari http://www.journal.stikespemkabjombang.a c.id/indeks.php/jikep pada tanggal 04 Maret 2019 pukul 13.00 WIB

Hou, Linping, Liu, Yaozhong. (2016). The Influence of Stressful Life Events of College Students on Subjective Well-Being : The Mediation Effect of the Operational Effectiveness. Open Journal of Sosial Sciences 2016 page 70-76. Diunduh dari http://www.file.scirp.org pada tanggal 21 Februari 2018 pukul 13.00 WIB 
Kallay, E., \& Baban, A., (2008). Emotional Benefits Of Expressive Writing In a Sample Of Romanian Female Cancer Patients, XII (1), 115-129. Diunduh dari http://www.googlescholar.com pada tanggal 15 Februari 2019 pukul 12.00 WIB

Mufadhal, Barseli; Ifdil; Nikmarijal (2017). Konsep Stres Akademik Siswa. Jurnal Konseling dan Pendidikan. Volume 5 Nomor 3 Halaman 143-148. Diunduh dari website http:www.google.com pada tanggal 5 Januari 2019 pukul 09.00 WIB

Muhtadini, Rahmita Laily (2018). Expressive Writing untuk Menurunkan Stres Akademik pada Siswa Sekolah Menengah Pertama (SMP) Full Day School. Skripsi. Diunduh dari website http:www.google.com pada tanggal 5 April 2019 pukul 09.00 WIB

Purwati, Susi. (2012). Tingkat Stres Akademik pada Mahasiswa Reguler Angkatan 2010 Fakultas Ilmu Keperawatan Universitas Indonesia. Skripsi. Tidak dipublikasikan. Diunduh dari website http:www.google.com pada tanggal 5 Januari 2019 pukul 09.00 WIB

Pennebaker, J.W., \& Francis, M.E. (1996). Cognitive, emotional and language processes in disclosure. Cognition and Emotion, 10, 601-626. Diunduh dari http://www.googlescholar.com pada tanggal 21 Februari 2019 pukul 12.00 WIB

Qanitatin, dkk. (2011). Pengaruh Katarsis dalam Menulis Ekspresif sebagai Intervensi Depresi Ringan pada Mahasiswa. Jurnal Psikologi. Volume 9 Nomor 1. Universitas Diponegoro. Diunduh dari http://www.googlescholar.com pada tanggal 01 Maret 2019 pukul 12.00 WIB

Rahmawati, Marieta. (2014). Menulis Ekspresif sebagai Strategi Mereduksi Stres untuk Anak-anak Korban Kekerasan dalam Rumah Tangga (KDRT). Jurnal Ilmiah Psikologi Terapan. Volume 02 Nomor 02 Januari 2014. Diunduh dari http://www.googlescholar.com pada tanggal 01 Maret 2019 pukul 12.00 WIB

Sindoro, Lidwina Florentiana. (2016). Efektivitas Expressive Writing sebagai Reduktor Psychological Distress. Skripsi. Universitas Sanata Dharma Yogyakarta. Diunduh dari http://www.googlescholar.com pada tanggal 01 Maret 2019 pukul 12.00 WIB

Zyga, S. (2013). Stress in Nursing Students. Internasional Journal of Caring Science. 6 (1). Diunduh dari http://www.googlescholar.com pada tanggal 21 Februari 2018 pukul 14.00 WIB 